\title{
A Chloride Selective Calix[4]arene Optical Sensor Combining Urea Functionality With Pyrene Excimer Transduction
}

\author{
Benjamin Schazmann \\ Technological University Dublin, benjamin.schazmann@tudublin.ie \\ Dermot Diamond \\ Dublin City University, dermot.diamond@dcu.ie
}

Follow this and additional works at: https://arrow.tudublin.ie/scschcpsart

Part of the Analytical Chemistry Commons, Materials Chemistry Commons, Organic Chemistry Commons, and the Physical Chemistry Commons

\section{Recommended Citation}

Schazmann, B., Alhashimy, N. \& Diamond, D. (2006) Journal of the American Chemical Society, 2006, Jul 5;128(26):8607-14. DOI: 10.1021/ja061917m

This Article is brought to you for free and open access by the School of Chemical and Pharmaceutical Sciences at ARROW@TU Dublin. It has been accepted for inclusion in Articles by an authorized administrator of ARROW@TU Dublin. For more information, please contact arrow.admin@tudublin.ie, aisling.coyne@tudublin.ie, gerard.connolly@tudublin.ie.

Funder: Enterprise Ireland, grant code SC/2002/161, Science Foundation Ireland for support under the Adaptive Information Cluster award (SFI03/IN3/1361) and the Environmental Protection Agency, Ireland, funding code EPA2004-RS-AIC-M4.

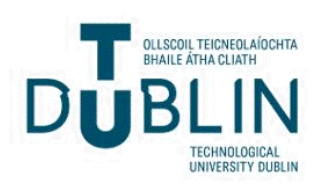




\title{
A Chloride Selective Calix[4]arene Optical Sensor
}

\section{Combining Urea Functionality With Pyrene Excimer}

\section{Transduction}

\author{
Benjamin Schazmann*, Nameer Alhashimy, and Dermot Diamond* \\ Adaptive Sensors Group, National Centre for Sensor Research, School of Chemical Sciences, Dublin \\ City University, Dublin 9, Ireland
}

Dermot.Diamond@dcu.ie and Benjamin.Schazmann2@mail.dcu.ie

ABSTRACT A neutral 2-site chloride selective compound has been developed (3), based on a 1,3alternate tetrasubstituted calix[4]arene providing a preorganised supramolecular scaffold. The resultant supramolecular cavity is amongst the first to combine urea functional groups bridged with single methylene spacers to pyrene moieties. It combines a naturally and synthetically proven H-bonding system with the elegant ratiometric fluorescent signalling properties of an intramolecular pyrene excimer system, triggered by conformational changes upon anion coordination. The excimer emission of $\mathbf{3}$ is quenched, with a simultaneous rise in the monomer emission solely by the chloride anion amongst a wide variety of anions tested. 3 has an association constant of $2.4 \times 10^{4} \mathrm{M}^{-1}$ with chloride. The suitability and advantages of ratiometric optical sensor compounds like $\mathbf{3}$ for use in practical sensor devices is discussed. 3 has an LOD of $8 \times 10^{-6} \mathrm{M}$ with chloride in acetonitrile-chloroform (95:5 v/v). A dynamic fluorescence study revealed a response time of $<3$ seconds. A recently developed and simple HPLC based purification method complimented conventional organic work up methods to yield pure product. 
KEYWORDS calixarene, fluorescence sensing, ratiometric, molecular recognition, chloride, anion sensor.

INTRODUCTION Compound $\mathbf{3}$ is part of a large and mature family of macrocyclic compounds called the calixarenes ${ }^{1-5}$. These supramolecular systems contain a central annulus which is largely aromatic in nature, and are typically substituted on the upper or lower rim of the annulus, resulting in effective host compounds for a wide variety of guests ${ }^{4,6-9}$. Calixarenes remain popular building blocks in host-guest chemistry due to the aesthetic and practical preorganised nature of the host cavity for target compounds. Host preorganisation is critical for successful host-guest chemistry, as it can provide a 'lock and key' basis for the sterric and electronic complimentarity between a host and guest manifested by thermodynamically favourable host-guest interactions ${ }^{10}$. The majority of calixarene hosts reported in the literature to date are cation hosts. Our own group have synthesized calixarene based hosts developing successful hosts for cations such as sodium ${ }^{11}$, calcium ${ }^{12}$ and lead ${ }^{13}$. There are now robust and selective commercially available cation sensors based on this chemistry.

Anion recognition is a growing field of research and there are good introductory texts and reviews available on the subject ${ }^{14-21}$. Adding hydrogen bond donor groups to organic hosts has been a key tool in providing recognition for specific anion geometries ${ }^{14,19}$. The urea and thiourea functional groups provide such effective and directional H-bonds for anion recognition. There are many examples of hosts that incorporate one or more urea group for anion binding, offering diverse binding geometries. Examples include open chain chelators or acyclic tweezers, tripodal and tetrapodal hosts. The structural design criteria for hosts in light of these geometries has been examined recently ${ }^{19}$. The field of supramolecular chemistry contains examples of larger cyclic structures containing cavities adorned with urea functionality such as cyclophanes ${ }^{22,23}$ and calixarenes ${ }^{24-35}$.

For urea based hosts, a major specific factor when considering anion-host interaction is the competition from the solvation of anion and host initially present. Another competing factor is the phenomenon of inter and intramolecular H-bonding between urea groups. These effects have been studied for calixarenes ${ }^{36-38}$. These bonds can be in direct competition with the detection of anions. For 
example Reinhoudt reported a tetrasubstituted urea calix[4]arene showing lower association constants and poorer anion selectivity than an equivalent disubstituted calix[4]arene, despite the availability of 8 and 4 hydrogen bonds respectively ${ }^{33}$. What may initially be considered a hindrance or a competing factor to the functioning of an anion sensor can reward the chemist by discriminating against some anions, thus creating interesting selectivity patterns.

The process of anion and cation recognition by calixarenes was typically monitored by NMR titrations or Ion Selective Electrode (ISE) studies. NMR spectroscopy typically provides important fundamental information about ion binding selectivity, stoichiometry and which molecular sites are involved in bonding, which is critical in understanding the host-guest interplay. In ISEs, the selectivity information generally mirrors that of NMR, although differences can occur, as NMR experiments are usually carried out in a particular solvent, whereas ISEs involve partition between a sample (aqueous) phase and the sensor membrane (PVC-organic) phase.

The placing of molecular components, which absorb and/or emit electromagnetic radiation (chromophores) in the proximity of the guest recognition site to yield an optical sensing compound, is an interesting strategy for host design, opening the way for alternative means of determining selectivity of a host. The binding of a guest causes an electronic or conformational change, which is signaled to the analyst optically.

More specifically, sensors involving fluorescence changes can draw on several advantages. This area has received much attention in the literature ${ }^{39-47}$. Such sensors can be simple in design with an excitation source and emission recorder as core features. They are mechanically relatively simple, with the advantages of not requiring reference elements and not requiring filling solutions as ISEs often $\mathrm{do}^{40}$. In analytical terms they can show very high sensitivity of detection often below micromolar levels down to a single molecule $\mathrm{e}^{47,48}$. Response times are typically extremely fast, they can be on-off switchable and where visible emission occurs the analyst has direct communication with the molecule by the naked eye.

The combination of molecular platforms with (thio)urea functionality crowned with fluorescent signal transduction provides the basis for powerful optical sensors for anions and has received much interest 
amongst researchers recently ${ }^{39,49-56}$. Fluorescent moieties available to the scientist are typically aromatics such as substituted benzenes, anthracenes, naphthalenes and pyrenes. Pyrenes are a particularly elegant basis for ratiometric based optical sensors, where the ratio of two emission wavelengths comprise the analytical signal ${ }^{57,58}$. To date the pyrene Excimer/monomer system has been exploited mainly for cation sensing ${ }^{59-70}$ and increasingly for anion sensing ${ }^{71-74}$. To the best of our knowledge there are few examples where pyrene and (thio)urea systems have been proximally combined in anion host compounds and none based on a calixarene platform ${ }^{75,76}$.

RESULTS AND DISCUSSION Typically the synthesis of a urea based target compound, including calixarenes, is advanced to a stage where there are one or more amine appendages present. The final stage is the addition of an appropriate isocyanate and under mild conditions (e.g. room temperature, 3 hours) the (thio)urea forms in good yield. The large number of isocyanates commercially available, mild reaction conditions and useful target properties make (thio)urea based hosts popular for anion detection.

A typical synthesis of $\mathbf{3}$ would normally have been performed starting from a tetranitrile calix[4]arene precursor via reduction to tetraamine and subsequent reaction with an appropriate isocyanate in the final step. As the necessary isocyanate was not readily available, the synthetic route depicted in Scheme 1 was chosen. 
Scheme 1. Synthetic routes to precursors $\mathbf{1}$ and $\mathbf{2}$ and calix[4]arene 3.
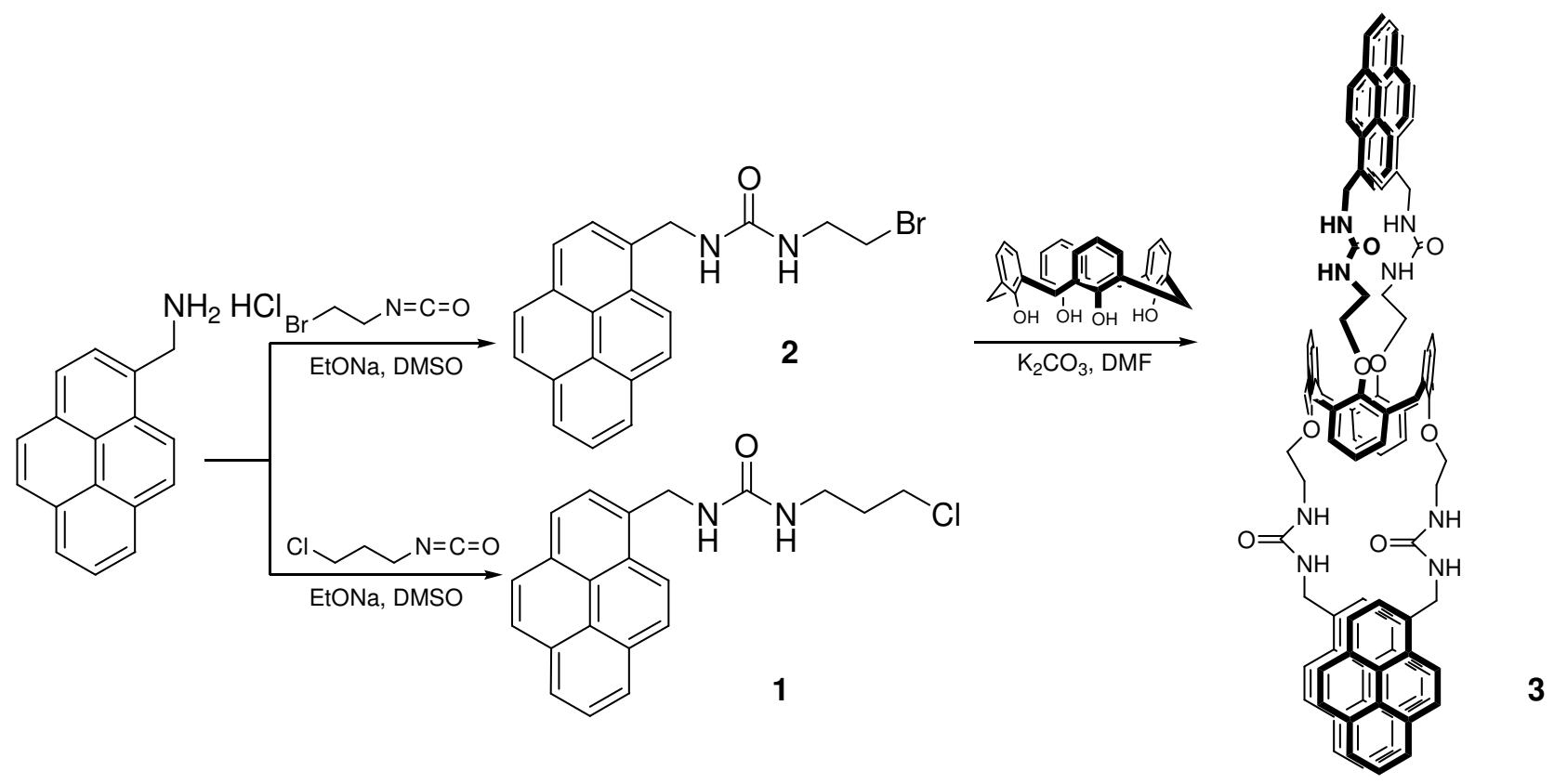

The pyrenyl urea appendages $\mathbf{1}$ and $\mathbf{2}$ were synthesized in one pot synthesis by the reaction of deprotonated 1-pyrenemethylamine hydrochloride with 3-chloropropyl and 2-bromoethyl isocyanates respectively. The obvious advantage is that precursors $\mathbf{1}$ and $\mathbf{2}$ represent 2 in 1 fluorophore-ionophore packages which can be fitted to other molecular scaffolds or precursors, besides calixarenes, yielding useful host compounds, possibly in a single reaction step. Interestingly, 1 did not react with calix[4]arene under the same conditions as the reaction of $\mathbf{2}$. Presumably as bromide is a better leaving group in substitution reactions, $\mathbf{2}$ is expected to be the more labile reagent. $\mathbf{2}$ was reacted with calix[4]arene by base induced $S_{N} 2$ substitution reaction to yield $\mathbf{3}$ in a further step. An initial qualitative screening of the crude mixture from this reaction by TLC, revealed a blue/green spot when the plate was irradiated with a long $\lambda(>300 \mathrm{~nm})$ UV light. This spot was not present in the TLC of 2 . Furthermore, the appearance of an excimer emission at $452 \mathrm{~nm}\left(\lambda_{\max }\right)$ was also seen only in the crude mixture of $\mathbf{3}$ by fluorescence screening. This was the first evidence that a compound with intramolecular pyrene interaction was present. Following initial workup of the reaction mix, a crude mixture containing $37 \% 3$ (of total peak areas) was present as shown by HPLC analysis. 
The crude workup products from the synthesis of $\mathbf{1 , 2}$ and $\mathbf{3}$ showed very poor solubility in most common solvents, marginally better solubility in $\mathrm{MeOH}$ and $\mathrm{ACN}$ and good solubility in DMSO or DMF. The preference for highly polar solvents is probably dictated by the polar urea groups and salts present. This affected the ease of purification of $\mathbf{2}$ and $\mathbf{3}$ in particular as chromatographic methods had to be used to achieve purity $>95 \%$. For 3 , an efficient semi-preparative HPLC method proved essential. This instrumental approach, previously developed in our group for supramolecule isolation, is of particular benefit when dealing with complex mixtures and low yielding reactions ${ }^{77}$. The method used was a fast efficient means of purifying mg quantities of a product using a scaled up analytical HPLC method based on widely available analytical instrumentation. A single pure peak remained as verified by HPLC, revealing an overall product purity of $98 \%$ (Figure S1).

From the ${ }^{1} \mathrm{H}$ NMR spectrum of $\mathbf{3}$, there is a single peak for the methylene groups of the calix[4]arene annulus. This is indicative of a 1,3-alternate structure as depicted in Scheme $1^{1}$. The attachment of 4 sterrically bulky appendages like 2 to a calix[4]arene platform may result in a deviation from the more common cone conformation to a less hindered 1,3-alternate configuration. This deviation from the cone conformations is particularly feasible as the calix[4]arene benzene groups are free to rotate through the central aromatic cavity, given the absence of the commonly present upper rim tertiary butyl groups. The two urea protons of start material 2 appeared deshielded from 6.3 and $6.8 \mathrm{ppm}$ into the aromatic region for 3. This signals a large change in the chemical environment of the urea protons in 3 . This deshielding of urea protons may be due to proximal pyrene moieties and increased inter or intramolecular H-bonding of the urea groups of $\mathbf{3}$.

A ${ }^{1} \mathrm{H}$ NMR temperature degradation study of $\mathbf{1}$ and $\mathbf{2}$ revealed that degradation generally occurred at temperatures of $80^{\circ} \mathrm{C}$ and above. Increased number of peaks and an increased integration numbers for aromatic protons suggested cleavage of the bulky pyrene moiety (Figure S2). The consequences of these findings were that a maximum temperature of only $70^{\circ} \mathrm{C}$ for the subsequent synthesis of $\mathbf{3}$ could be used. This coupled with the solubility and purification issues discussed above led to a final yield of only $2 \%$. 
The excitation spectrum of $\mathbf{1 , 2}$ and $\mathbf{3}$ revealed a $\lambda_{\max }$ of $340 \mathrm{~nm}$ as an ideal excitation wavelength. Figure 1 shows the emission spectrum of $\mathbf{2}$ and $\mathbf{3}$ in acetonitrile-chloroform $(95: 5 \mathrm{v} / \mathrm{v}) .2$ reveals two monomer emission peaks at $376 \mathrm{~nm}$ and $398 \mathrm{~nm}\left(\lambda_{\max }\right)$. There are no significant emission features $>430 \mathrm{~nm}$, indicating the absence of excimer formation. $\mathbf{3}$ shows the monomer emissions as well as a much larger broad emission band at $452 \mathrm{~nm}\left(\lambda_{\max }\right)$, characteristic of an intramolecular pyrene excimer emission.

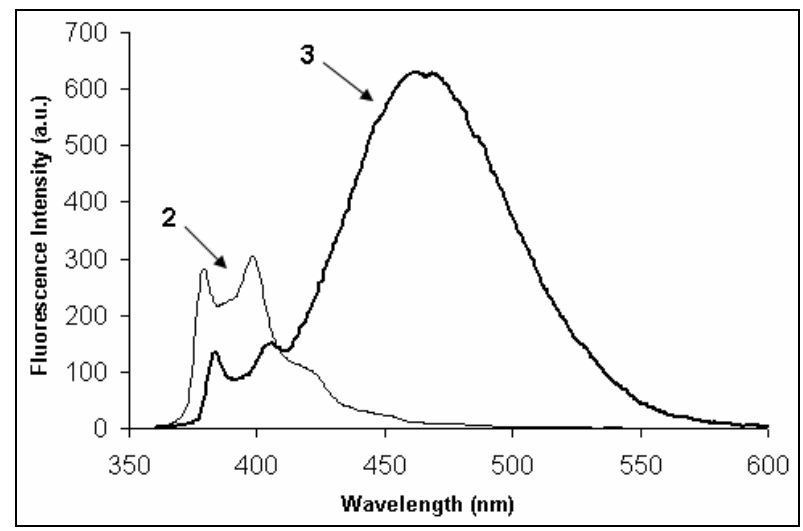

Figure 1. Emission spectra of 2 and $3\left(1 \times 10^{-6} \mathrm{M}\right)$ in acetonitrile-chloroform $(95: 5 \mathrm{v} / \mathrm{v})$ showing monomer maxima at $376 \mathrm{~nm}$ and $398 \mathrm{~nm}$. Only $\mathbf{3}$ shows an additional large band at $452 \mathrm{~nm}$ due to excimer formation. (The excitation wavelength was $340 \mathrm{~nm}$. )

Only the pure fraction of $\mathbf{3}$, unlike the fluorescence spectra of $\mathbf{1 ,} \mathbf{2}$ and all the other fractions collected during the purification of $\mathbf{3}$ by semi-preparative HPLC, revealed the characteristically broad pyrene excimer emission.

For 3, the ratio of excimer $(452 \mathrm{~nm})$ to monomer $(398 \mathrm{~nm})$ emission remained unchanged at 4.4 in the concentration range $1 \times 10^{-7}$ to $1 \times 10^{-5} \mathrm{M} 3$. This further confirmed the presence of pyrene units interacting by an intramolecular mechanism, not an intermolecular one.

The ditopic chromoionophore $\mathbf{3}$ is built on a calix[4]arene platform, lending preorganisation to the overall host. Four urea groups providing eight possible H-bonds for anion binding are in close proximity to pyrene moieties, whose orientation relative to each other is thought to change upon guest 
inclusion. Such a binding event is thus monitored by ratiometric changes in the emission spectrum (Excimer:Monomer ratio) of $\mathbf{3}$.

The changes in the emission spectrum of $\mathbf{3}$ were examined when screened with eleven common anions. These spanned a comprehensive range of sizes and shapes. 100 equivalents of the tertiary butyl ammonium salt of each anion was added to $1 \times 10^{-6} \mathrm{M}$ solutions of $\mathbf{3}$ in acetonitrile-chloroform (95:5 $\mathrm{v} / \mathrm{v})$. The change in excimer and monomer emission was monitored and the results tabulated in Table 1.

Table 1. Fluorescence changes ( $\left(\mathrm{I}-\mathrm{I}_{0}\right)$ for $\mathbf{3}$ upon addition of 100 equivalents of specified anion ${ }^{\mathrm{a}}$.

\begin{tabular}{ccccccccccccccc}
\hline \multicolumn{10}{c}{ Fluorescence change $\left(\mathrm{I}-\mathrm{I}_{0}\right)$} \\
\hline$\lambda_{\text {em }}(\mathbf{n m})$ & $\mathrm{Cl}^{-}$ & $\mathrm{F}^{-}$ & $\mathrm{Br}^{-}$ & $\mathrm{I}^{-}$ & $\mathrm{NO}_{3}^{-}$ & $\mathrm{ClO}_{4}^{-}$ & $\mathrm{AcO}^{-}$ & $\mathrm{SCN}^{-}$ & $\mathrm{CN}^{-}$ & $\mathrm{HSO}_{4}^{-}$ & $\mathrm{H}_{2} \mathrm{PO}_{4}^{-{ }^{-}}$ & $\mathrm{H}_{2} \mathrm{O}^{\mathrm{b}}$ \\
$\mathbf{3 9 8}$ & +270 & -7 & 0 & -6 & -6 & -1 & +2 & -8 & +2 & 0 & +6 & -36 \\
$\mathbf{4 5 2}$ & -591 & +2 & +5 & -1 & -4 & +6 & -4 & 0 & -8 & -5 & -3 & +36
\end{tabular}

${ }^{a}$ Conditions: 3, $1.6 \times 10^{-6} \mathrm{M}$ in acetonitrile-chloroform $(95: 5 \mathrm{v} / \mathrm{v})$, excitation at $340 \mathrm{~nm}$. $\mathrm{I}_{\mathrm{o}}$ : fluorescence emission intensity of free 3. I: fluorescence emission intensity of $\mathbf{3}$ with 100 equivalents of specified anion in the form of tertiary butyl ammonium salts. ${ }^{\mathrm{b}} 1000$ equivalents added.

Remarkably, only chloride caused a dramatic change in the emission spectrum of $\mathbf{3}$. There is a sharp decline in excimer emission with a corresponding increase in monomer emission. These observations suggest that the chloride anion appears to selectively coordinate with the urea protons in the cavity of $\mathbf{3}$ so as to 'unstack' or lever apart, the facing $\pi-\pi$ stacked pyrenes. This conformational change is depicted in Scheme $2^{\mathrm{i}}$. The 'unstacking' of the pyrene moieties is justified by the strong reduction of the excimer emission spectrum upon complexation of chloride. 
Scheme 2. The binding of chloride ions by 3. Quenching of Excimer emission (452nm) caused by a perturbation of the pyrene $\pi-\pi$ interaction by the conformational 'unstacking' of pyrene moieties.
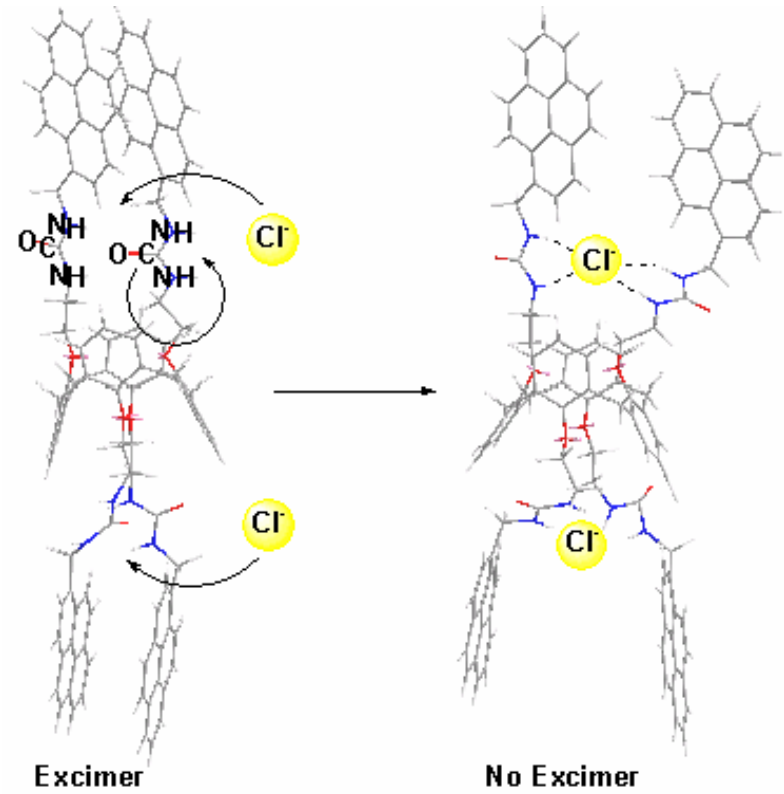

The excimer emission of $452 \mathrm{~nm}\left(\lambda_{\max }\right)$ signifies a considerable blue shift compared to other intramolecular pyrene excimer systems, which typically show a $\lambda_{\max }$ of $480 \mathrm{~nm}^{57}$. The comparison of the pyrene excimer emission of sandwich-like systems (full overlap) with partially overlapping systems is normally explained in this way ${ }^{78,79}$. Sandwich-like systems are described as dynamic excimers, in that pyrene moieties are free to fully overlap. Partially overlapping pyrenes are described as static because some force is inducing a partial overlap. In the case of free $\mathbf{3}$, there is a strong likelihood of H-bonding between urea groups in addition to sterric factors, thereby offering a plausible explanation for the observed partially overlapped static excimer.

To further support the mode of binding proposed, selected tetrabutylammonium anions were added in excess to 3 in deuterated acetone (Figure S3). Only the chloride salt caused a downfield shift of urea protons, indicative of an $\mathrm{H}$-bonding interaction. Upon addition of 300 equivalents of $\mathrm{Cl}^{-}$, the two triplet signals for the urea protons appear shifted downfield, clear of the main aromatic region at $8.69 \mathrm{ppm}$ and 8.71ppm. This shows clearly that chloride ions form an inclusion complex within the cavities of $\mathbf{3}$ involving urea protons. No such discernible change was observed for the smaller fluoride and the larger 
bromide anions, confirming chloride selectivity. These results mirror the findings of the fluorescence study, where a response appeared exclusive to $\mathrm{Cl}^{-}$.

Furthermore, the aromatic protons of $\mathbf{3}$ appear considerably deconvoluted by the addition of $\mathrm{Cl}^{-}$, suggesting a more symmetrical complex structure compared to the free Host. The separation of previously $\pi$-stacked pyrene moieties appears to reduce the influence of the $\pi$-electron clouds from the planes of the pyrene moieties on ${ }^{1} \mathrm{H}$ NMR peak splitting and chemical shifts. It appears that a specific cavity effect controls the anion binding characteristics of $\mathbf{3}$. A 'lock and key' or 'best fit' model appears to yield an energetically favorable host-guest interaction for chloride in this case. This is in contrast to a scenario where an anion host offers little preorganisation, where selectivity is typically dictated by anion basicity $^{15}$.

When 0-500 equivalents of chloride are added to $\mathbf{3}$, the change in emission can be followed and is shown in Figure 2.
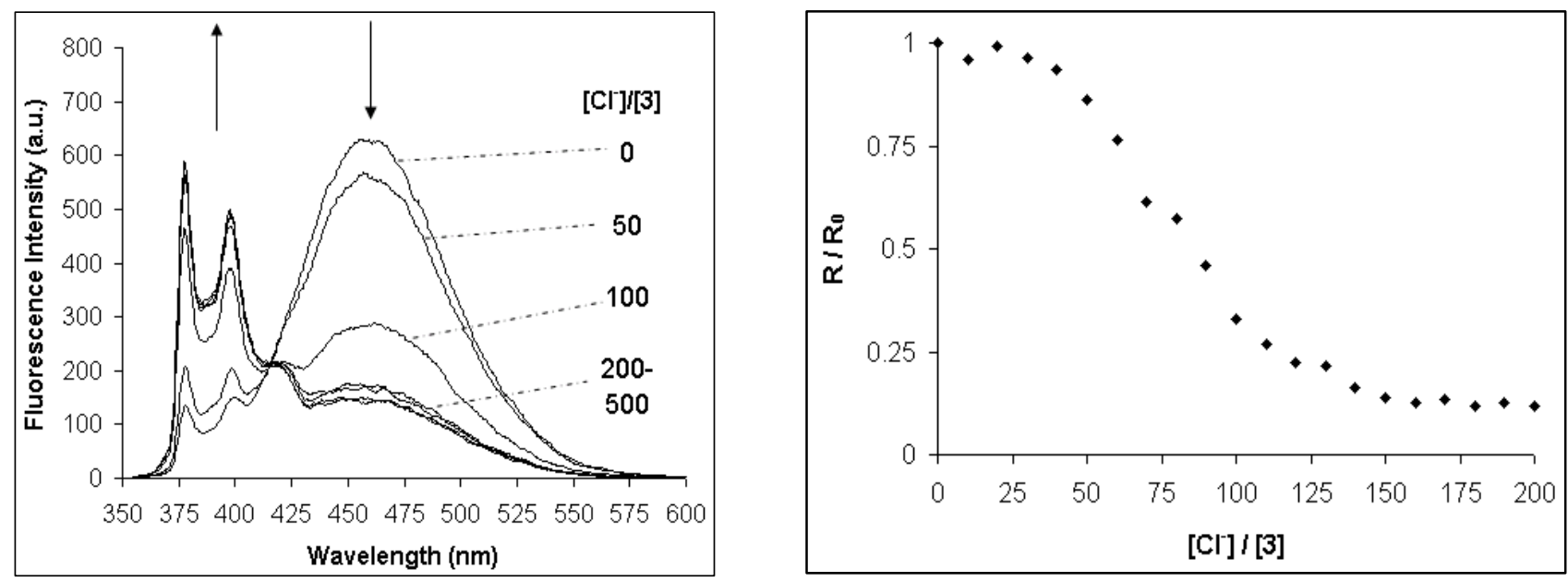

Figure 2. Changes of the fluorescence spectrum of a $1 \times 10^{-6} \mathrm{M}$ molar solution of $\mathbf{3}$ in acetonitrilechloroform $(95: 5 \mathrm{v} / \mathrm{v})$ upon addition of the specified number of equivalents of chloride $\left(\left[\mathrm{Cl}^{-}\right] /[3]\right) . \quad \mathrm{R}_{0}$ : Ratio of excimer $\left(\lambda_{\mathrm{em}}=452 \mathrm{~nm}\right)$ to monomer $\left(\lambda_{\mathrm{em}}=398 \mathrm{~nm}\right)$ of free 3. R: Ratio of excimer to monomer with varying $\left[\mathrm{Cl}^{-}\right]$. (The excitation wavelength was 340nm.)

At $412 \mathrm{~nm}$ there is an isoemissive point which indicates that only one type of complexing mechanism (equivalent in both cavities of $\mathbf{3}$ ) is at play perturbing the excimer emission of $\mathbf{3}^{72}$. From the change in 
excimer to monomer ratios observed with chloride added, an association constant of $2.4 \times 10^{4} \mathrm{M}^{-1}$ was obtained $^{\mathrm{ii}}$.

The association constants of well known crown and cryptand alkali metal hosts are typically about $10^{6} \mathrm{M}^{-1}$ and $10^{10} \mathrm{M}^{-1}$ respectively ${ }^{10}$. It appears that selective anion hosts seldom reach association constants of this magnitude and are in fact lower by several orders of magnitude, due to factors competing with anion complexation as discussed in the introduction. Additional factors competing with anion coordination specific to 3 may include the cost in energy to separate the overlapping pyrene $\pi-\pi$ bonding systems. The sterrically bulky nature of pyrene moieties also aids in the discrimination between anions. In addition, as each equivalent di-urea cavity of $\mathbf{3}$ binds a chloride anion, the resultant repulsion between these two ions of same charge within $\mathbf{3}$ may further lower the overall association constant. However, in general, the net effect of the competing factors responsible for low association constants may also be contributing factors for good selectivity. The selectivity of $\mathbf{3}$ towards chloride can also be explained classically by a 'best fit' or 'lock and key' model. It is most likely several cumulative factors that contribute to what is ultimately the most important parameter of a sensor design: Selectivity.

Few works discussing the combination of urea anion binding sites with pyrenes were found in the literature. Sasaki synthesized a tripodal anion host with pyrenes directly adjacent to 3 thiourea groups ${ }^{75}$. In terms of selectivity, Sasaki did not observe a unique selectivity but some deviation from a typical selectivity order, following anion basicity. Werner describes nucleotide anion hosts which have relatively long propyl spacers between pyrene moieties and ureas ${ }^{76}$. The separation of $\pi$-stacked pyrenes and simultaneous anion binding could not be observed.

A developer of practical fluorescent probes or sensors can choose from three broad fluorescence signal types $^{80}$. Intensity based probes rely on the change of intensity of single wavelengths. The biggest disadvantage here is that for accurate sensing, the exact probe host concentration must be known. Typically factors like host degradation or leaching into the sample result in ever changing host concentration. Other factors like sample turbidity, intensity of incident light, scattering, inner-filter effects and photo bleaching strongly affect the signal reliability. These disadvantages are largely absent 
for the other two categories, life-time based and wavelength-ratiometric fluorescent sensing methods. 3 belongs to the latter class.

It is apparent from the literature that there are quite a number of fully characterized fluorescent sensor compounds available with elegant spectroscopic properties. The operating wavelengths of many of these compounds, including 3 (excitation 340nm), fall within the UV region of the spectrum. A major challenge for developing fluorescent sensor devices from these compounds are optically compatible sensor materials ${ }^{40,81-83}$. Many currently available materials can contribute to interferences and auto fluorescence of a sensor, particularly in the UV region $(<400 \mathrm{~nm})$. The search is on then to continue to lower the UV transparency cutoff point of components. One such component, central to any fluorescent optical sensor is an excitation source and an emission detector. Laser diodes and Light Emitting Diodes (LEDs) lead the field when it comes to developing miniaturized, cheap and effective sensor devices ${ }^{84}$. As material scientists work to increase the UV-transparency of device components, organic chemists strive to raise the 'useful' wavelengths of a sensor compound towards the visible region. In future it is hoped that these efforts will converge. Both monomer and excimer emission intensities of $\mathbf{3}$ at a concentration of $1 \times 10^{-6} \mathrm{M}$ were found to be about $75 \%$ and $10 \%$ at excitation wavelengths of $350 \mathrm{~nm}$ and 360nm respectively, compared to an excitation wavelength of 340nm. Despite decreased intensities, analytically useful signals were still obtained. With an effective wavelength range of $360-460 \mathrm{~nm}$, a host like 3 may soon have analytical potential. Indeed, there are LEDs available commercially at the time of writing that operate at predefined wavelengths from the visible down into the UV range as low as $350 \mathrm{~nm}$ and lower all the time $\mathrm{iii}^{\mathrm{ii}}$.

A system where a bulk 1:1 Host to Guest concentration results in a plateau of the measured signal upon further addition of guest is best described as a switch. Conversely, $\mathbf{3}$ displayed a range of response of about $5 \times 10^{-5} \mathrm{M}$ to $1.5 \times 10^{-4} \mathrm{M}$ chloride (50-150 equivalents of chloride added to $1 \times 10^{-6} \mathrm{M}$ of $\mathbf{3}$ ) as seen in Figure 2. The larger the response range of a sensor, the easier it is to tune a device to yield both qualitative and quantitative data on a guest and the more it lends itself to continuous sensing ${ }^{40}$. 
Chloride (usually from sodium chloride) is essential for human health with typical levels at $0.1 \mathrm{M}$ in blood serum. In soil typical levels are $100 \mathrm{ppm}^{85}$. The typical chloride levels in the oceans are about $0.5 \mathrm{M}^{86}$. For these applications a particularly low LOD is not required. For the many other analytes however, ever lower LODs are essential, several orders of magnitude below the above examples.

The upper and lower LODs and linear response ranges of systems like $\mathbf{3}$ can be tuned to a certain degree. At the minimum instrument sensitivity settings signal saturation was observed above $10^{-5} \mathrm{M} 3$. Down to concentrations of $1 \times 10^{-8} \mathrm{M} \mathrm{3}$, analytically useful excimer/monomer bands are still observed (Figure S4), using the maximum sensitivity threshold of the instrumentation used. Based on this concentration an LOD of $8 \times 10^{-6} \mathrm{M}$ chloride was observed. This amounts to a chloride concentration that is only 6-fold lower than the LOD for a starting concentration of $1 \times 10^{-6} \mathrm{M} \mathrm{3}$. A reduced excimer:monomer ratio of around 3.0 was observed for $\mathbf{3}$, leaving less scope for signal change on complexation. Furthermore at concentrations of $1 \times 10^{-8} \mathrm{M} \mathrm{3}$, the monomer-excimer signals are likely to be more prone to baseline interference and errors. Indeed 800 equivalents of chloride were needed to get a reproducible signal change at the lower concentration of $\mathbf{3}$.

Where upper or lower LOD changes are required for ratiometric fluorescence sensors incorporating hosts like $\mathbf{3}$, it is perhaps also useful to carefully adjust other sensor parameters. Such a strategy may involve starting with a constant concentration of 3 in the range $1 \times 10^{-7}$ to $1 \times 10^{-5} \mathrm{M}$, where an optimal high excimer:monomer ratio of 4.4 was observed. By carefully tuning the sensor sample pathlength, characteristics of source and detector (LEDs, photodiodes etc.) or excitation/emission bandwidths for example, the sensitivity towards the analyte could be modulated. If the host is incorporated into a liquid polymer membrane, the polarity of this environment via choice of polymer or plasticizer for example can also have a profound effect on analyte sensitivity.

In a dynamic analyte environment, response time is important. A dynamic experiment involving $\mathbf{3}$ was carried out. A sample of $1 \times 10^{6} \mathrm{M} 3$ was spiked with 100 equivalents of chloride and the response measured over time. No mechanical stirring was provided. Once again a strong chloride response was observed, with a stable final emission signal after about 3 seconds as seen in Figure 3. 


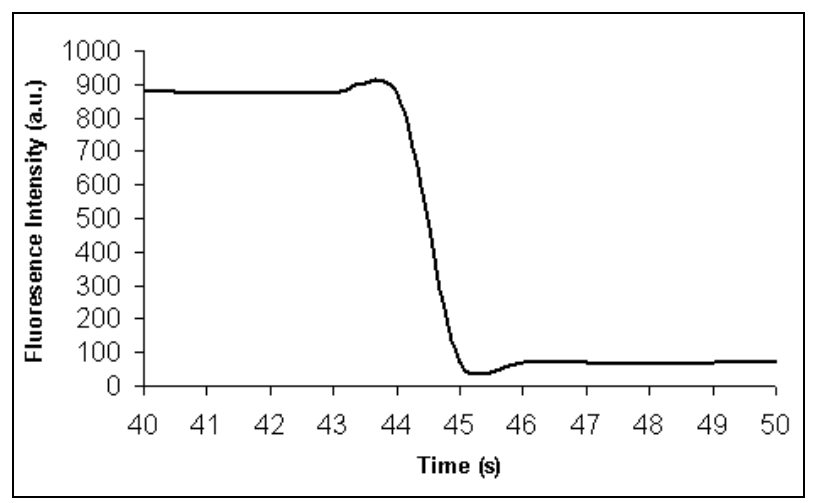

Figure 3. The dynamic response of a $1 \times 10^{6} \mathrm{M}$ solution of $\mathbf{3}$ when spiked with 100 equivalents of chloride. Excitation 350nm and bandwidth 5nm. Fluorescence was monitored at 452nm. With no mechanical stirring, a stable signal was obtained in about 3 seconds.

Most useful sensors must be able to operate in an aqueous environment. This is immediately clear when considering environmental and medical applications. When 1000 equivalents of water were added to 3 as seen in Table 1, there was no reduction in the excimer emission and so it is not in direct competition with chloride complexation. On the contrary, the excimer:monomer ratio increased to 4.8. Water may enhance the pyrene $\pi-\pi$ interactions possibly due to an increase in aggregation of organic moieties in an environment of increasing polarity. We are currently conducting experiments in solvent systems with increasing proportions of water.

When considering incorporating a host compound into a chemical sensor, this typically involves either the mixing of the compound into a hydrophobic polymeric membrane cocktail (e.g. PVC membrane of an Ion Selective Electrode) or covalent attachment to a polymer backbone or other substrate. The latter approach has the main advantage that it can prevent leaching of the compound into the sample matrix during analysis. Neutral calixarenes based hosts are ideal for both strategies. As calixarenes present numerous substitution opportunities at the upper and lower rim, calixarenes can for example be copolymerised into polymer backbones with the aid of passive linkers. In tandem, active complexing substituents can operate independently. One sample strategy is via the upper rim which may be converted to $p$-allyl groups prior to functionalising the lower $\operatorname{rim}^{87-89}$. Labile $p$-allyl groups are then copolymerised onto a polymer and thereby securely 'fastened' to the sensor substrate. 
In time, it is envisaged that with the current pace of progress, ratiometric receptors like $\mathbf{3}$ and similar systems in the literature may soon see applications in real life devices.

EXPERIMENTAL SECTION 1-(3-chloropropyl)-3-(pyren-1-yl methyl)urea (1). Under argon, 1pyrenemethylamine hydrochloride $(3.00 \mathrm{~g}, 11.20 \mathrm{mmol})$ and sodium ethoxide $(0.84 \mathrm{~g}, 12.32 \mathrm{mmol})$ was stirred in $200 \mathrm{ml}$ dry DMSO for 1 hour at room temperature. 3-Chloropropyl isocyanate $(1.26 \mathrm{ml}$, $12.32 \mathrm{mmol}$ ) was added to the vessel and stirring continued for a further 12 hours at room temperature. A bulky white solid was obtained by filtering the mixture. The solution was cooled on ice and $200 \mathrm{ml}$ water at $0^{\circ} \mathrm{C}$ was added slowly yielding a white ppt. After filtering, the filtrate was washed 3 times with $20 \mathrm{ml}$ aliquots of $0{ }^{\circ} \mathrm{C}$ de-ionised water and 3 times with $10 \mathrm{ml}$ aliquots of $\mathrm{MeOH}$ at $0{ }^{\circ} \mathrm{C}$. Upon drying, $3.01 \mathrm{~g}(77 \%)$ of 1 was obtained as a white solid. mp: $195-200{ }^{\circ} \mathrm{C}$. IR (KBr): $3320,1619,655 \mathrm{~cm}^{-1} .1 \mathrm{H}$ NMR (400MHz, $\left.\mathrm{CD}_{3} \mathrm{COCD}_{3}\right): 8.00-8.50(\mathrm{~m}, 9 \mathrm{H}, \mathrm{ArH}), 6.56\left(\mathrm{t}, 1 \mathrm{H}, \mathrm{ArCH}_{2} \mathrm{NH}, \mathrm{J}=5.6\right), 6.12(\mathrm{t}, 1 \mathrm{H}$, $\left.\mathrm{CH}_{2} \mathrm{CH}_{2} \mathrm{NHCO}, \mathrm{J}=5.6\right), 4.96\left(\mathrm{~d}, 2 \mathrm{H}, \mathrm{ArCH}_{2} \mathrm{NH}, J=5.6\right), 3.65\left(\mathrm{t}, 2 \mathrm{H}, \mathrm{CH}_{2} \mathrm{CH}_{2} \mathrm{Cl}, J=6.4\right), 3.18(\mathrm{~m}, 2$ $\left.\mathrm{H}, \mathrm{NHCH}_{2} \mathrm{CH}_{2}, \mathrm{~J}=6.4\right), 1.85\left(\mathrm{~m}, 2 \mathrm{H}, \mathrm{CH}_{2} \mathrm{CH}_{2} \mathrm{CH}_{2}, \mathrm{~J}=6.4\right) .{ }^{13} \mathrm{C} \mathrm{NMR}\left(50 \mathrm{MHz}, \mathrm{CD}_{3} \mathrm{COCD}_{3}\right): 158.4$, $134.7,131.2,130.7,130.3,128.3,127.8,127.2,126.6,125.5,125.1,124.4,124.3,123.6,43.4,41.5$, 40.7, 37.2, 33.3 ppm. ESI MS +m/e $373.2\left(\left[\mathrm{M}+\mathrm{Na}^{+}\right]\right.$, calcd 373.1). Anal. Calcd for $\mathrm{C}_{21} \mathrm{H}_{19} \mathrm{ClN}_{2} \mathrm{O}: \mathrm{C}$, 71.89; H, 5.46; N, 7.98. Found: C, 71.94; H, 5.14; N, 7.77. HPLC purity: 96.0\%.

1-(2-bromoethyl)-3-(pyren-1-yl methyl)urea (2). Under argon, 1-pyrenemethylamine hydrochloride $(10.00 \mathrm{~g}, 37.35 \mathrm{mmol})$ and sodium ethoxide $(2.80 \mathrm{~g}, 41.10 \mathrm{mmol})$ were stirred in $700 \mathrm{ml}$ dry DMSO for 1 hour at room temperature. 2-Bromoethyl isocyanate $(3.71 \mathrm{ml}, 41.10 \mathrm{mmol})$ was added to the vessel and stirring continued for a further 12 hours at room temperature. The solution was cooled on ice and $700 \mathrm{ml}$ water at $0^{\circ} \mathrm{C}$ was added slowly yielding a white ppt. After filtering, the filtrate was washed 3 times with $50 \mathrm{ml}$ aliquots of $0{ }^{\circ} \mathrm{C}$ de-ionised water and 3 times with $20 \mathrm{ml}$ aliquots of $\mathrm{MeOH}$ at $0{ }^{\circ} \mathrm{C}$. Chromatography on silica gel with EtOAc-hexane (1/3) as eluent gave 3.29g (23\%) of 2 as a white solid. mp: $155-160{ }^{\circ} \mathrm{C} . \quad \mathrm{IR}(\mathrm{KBr}): 3322,1622,626 \mathrm{~cm}^{-1}$. $1 \mathrm{H} \mathrm{NMR}\left(400 \mathrm{MHz}, \mathrm{CD}_{3} \mathrm{C} 0 \mathrm{CD}_{3}\right): 8.00-8.50$ (m, 9 $\mathrm{H}, \operatorname{Ar} H), 6.84\left(\mathrm{t}, 1 \mathrm{H}, \operatorname{ArCH}_{2} \mathrm{NH}, \mathrm{J}=5.6\right), 6.35\left(\mathrm{t}, 1 \mathrm{H}, \mathrm{CH}_{2} \mathrm{CH}_{2} \mathrm{NHCO}, \mathrm{J}=5.6\right), 5.00(\mathrm{~d}, 2 \mathrm{H}$, $\left.\mathrm{ArCH}_{2} \mathrm{NH}, J=6.0\right), 3.66\left(\mathrm{t}, 2 \mathrm{H}, \mathrm{CH}_{2} \mathrm{CH}_{2} \mathrm{Br}, J=6.2\right), 3.43\left(\mathrm{~m}, 2 \mathrm{H}, \mathrm{NHCH}_{2} \mathrm{CH}_{2}, J=6.2\right) .{ }^{13} \mathrm{C} \mathrm{NMR}$ 
$\left(50 \mathrm{MHz}, \mathrm{CD}_{3} \mathrm{COCD}_{3}\right): 157.9,134.1,130.9,130.2,129.8,127.7,127.3,126.9,126.2,125.1,124.5$, 123.9, 123.0, 44.5, 41.2, 41.0 ppm. ESI MS +m/e 383.1 ([M + $\left.\mathrm{H}^{+}\right]$, calcd 383.1). HPLC purity: 95.4\%.

25,26,27,28-tetrakis[[ $N$-(1-pyrenylmethylureido)ethyl]oxy]calix[4]arene (3). Under argon, $p$-tertbutylcalix[4]arene $(1.00 \mathrm{~g}, 1.54 \mathrm{mmol})$ and $\mathrm{K}_{2} \mathrm{CO}_{3}(0.85 \mathrm{~g}, 6.16 \mathrm{mmol})$ were heated in $100 \mathrm{ml}$ DMF for 3 hours at $70{ }^{\circ} \mathrm{C} .2(2.36 \mathrm{~g}, 6.16 \mathrm{mmol})$ was added and the reaction progress monitored by HPLC. No further reaction occurred after 2 days. The solution was cooled on ice and $100 \mathrm{ml}$ de-ionised water at 0 ${ }^{\circ} \mathrm{C}$ was added to yield a beige ppt. The product was extracted from the solid with $310 \mathrm{ml}$ aliquots of chloroform. The combined chloroform aliquots were washed with $310 \mathrm{ml}$ aliquots of de-ionised water. The resultant chloroform layers were combined, dried with $\mathrm{Na}_{2} \mathrm{SO}_{4}$ and reduced to $2 \mathrm{ml}$ by evaporation. This solution was shown to contain $37 \% \mathbf{3}$ by HPLC. Purification by semi-preparative HPLC gave $0.04 \mathrm{~g}(2.03 \%) 3$ as a white solid (supporting information). mp: $190-191{ }^{\circ} \mathrm{C}$. IR (KBr): $3320,1690 \mathrm{~cm}^{-}$ 1. 1H NMR (400MHz, $\left.\mathrm{CD}_{3} \mathrm{COCD}_{3}\right): \delta 8.30-7.91$ (m, $36 \mathrm{H}, \mathrm{ArH}$, pyrene), 8.30-7.91 (t, $4 \mathrm{H}$, urea), 8.30$7.91(\mathrm{t}, 4 \mathrm{H}$, urea), $7.84(\mathrm{~d}, 4 \mathrm{H}, \operatorname{Ar} H), 7.55(\mathrm{~d}, 4 \mathrm{H}, \operatorname{Ar} H), 7.68(\mathrm{~m}, 4 \mathrm{H}, \operatorname{Ar} H)), 5.11(\mathrm{~d}, 8 \mathrm{H}$, $\left.\mathrm{ArCH}_{2} \mathrm{NHCO}, J=5.6\right), 5.02\left(\mathrm{~s}, 8 \mathrm{H}, \mathrm{ArCH}_{2} \mathrm{Ar}\right), 4.54\left(\mathrm{t}, 8 \mathrm{H}, \mathrm{NHCH}_{2} \mathrm{CH}_{2}, J=6.8\right), 4.07(\mathrm{t}, 8 \mathrm{H}$, $\left.\mathrm{NHCH}_{2} \mathrm{CH}_{2} \mathrm{O}, J=6.8\right) .{ }^{13} \mathrm{C} \mathrm{NMR}\left(50 \mathrm{MHz}, \mathrm{CD}_{3} \mathrm{COCD}_{3}\right): 153.8,152.2,135.8,133.9,132.6,132.07$, $131.4,129.9,128.9,128.7,128.4,128.0,127.3,126.5,126.2,126.0,125.8,124.5,124.2,66.1,49.3$, 44.7, 42.8 ppm. Anal. Calcd for $\mathrm{C}_{108} \mathrm{H}_{88} \mathrm{~N}_{8} \mathrm{O}_{8}:$ C, 79.78; H, 5.46; N, 6.89. Found: C, 80.10; H, 5.11; N, 6.86. HPLC purity: $97.8 \%$.

Method for analytical and semi-preparative HPLC. HPLC was carried out using a HP1050 instrument with UV detection. Mobile phase used was HPLC grade methanol in isocratic mode. Chloroform served as the sample solvent. Detection wavelengths were $210 \mathrm{~nm}$ and $340 \mathrm{~nm}$. For analytical HPLC, a Synergy $150.0 \times 2.0 \mathrm{~mm}, 4 \mu \mathrm{m}$ Fusion-RP column was used. Flowrate was $0.2 \mathrm{ml} / \mathrm{min}$. Injection volume was $10 \mu \mathrm{l}$. For semi-preparative HPLC, a Synergy $250.0 \times 10.0 \mathrm{~mm}, 10 \mu \mathrm{m}$ Fusion-RP column was used. Flowrate was $5.0 \mathrm{ml} / \mathrm{min}$. Injections volume was $100 \mu \mathrm{l}$ filtered sample. Fraction collection was carried out manually or with a Gilson 204 fraction collector in automation mode. 
For LC-MS and direct injection MS work, a Bruker/Hewlard-Packard Esquire system, using a positive ESI source and the software's default 'smart' settings. For direct injection MS work the solvent used was MS grade acetonitrile with a $0.25 \%$ formic acid content.

General details for absorption and fluorescence studies. UV/Vis absorption spectra were recorded using a Perkin Elmer model Lambda $900 \mathrm{UV}-\mathrm{Vis}$ spectrophotometer. Fluorescence spectra were recorded with a Perkin Elmer luminescence spectrometer model LS50B. In all cases, $1 \mathrm{~cm}$ quartz cuvettes were used. $1 \times 10^{5} \mathrm{M}$ stock solutions of $\mathbf{1 , 2}$ and $\mathbf{3}$ were prepared in acetonitrile-chloroform $(95: 5 \mathrm{v} / \mathrm{v})$. For ratiometric complexation studies, $0.01 \mathrm{M}$ stock solutions of the tetrabutylammonium salt of each anion were prepared in acetonitrile-chloroform $(95: 5 \mathrm{v} / \mathrm{v})$. For all fluorescence work, an excitation wavelength of $340 \mathrm{~nm}$ was chosen with excitation and emission slits at $3 \mathrm{~nm}$ unless stated otherwise. For fluorescence titrations and dynamic response time measurements, $1 \times 10^{6} \mathrm{M}$ solutions of 3 were used, adding the appropriate volume of the $0.01 \mathrm{M}$ chloride stock solution. From the change in excimer $(452 \mathrm{~nm})$ to monomer $(398 \mathrm{~nm})$ ration with chloride added, the association constant was calculated by non-linear regression analysis and the fitting of experimental data with a standard fluorescence equation by minimizing the sum of square residuals. The standard Microsoft Excel add-in SOLVER was used. The LOD of chloride for $\mathbf{3}$ was calculated by observing the decrease in excimer and increase in monomer emissions of decreasing concentrations of $\mathbf{3}$, upon addition of chloride. The LOD was considered the lowest concentration of chloride that caused a change in both the monomer and excimer intensities, greater than three times the standard deviation of the baseline noise intensities of free 3. Excitation and emission slits were $15 \mathrm{~nm}$ for LOD work, the maximum permissible by the instrument used.

Procedure for binding site investigation by ${ }^{\mathbf{1}} \mathbf{H}$ NMR. A $1.6 \mathrm{mM}$ solution of 3 in deuterated acetone was prepared. To $1 \mathrm{ml}$ of this solution, 300 equivalents of tetrabutylammonium anion were added and the main chemical shifts noted.

Temperature degradation study of 1,2 and 3 by ${ }^{1} \mathbf{H}$ NMR. A $1.6 \mathrm{mM}$ solution of each compound in the relevant NMR solvent was placed in a temperature control oven in anhydrous conditions and left for 
12 hours at incremental temperatures between $30^{\circ} \mathrm{C}$ and $100^{\circ} \mathrm{C}$. Following a return to room temperature, the spectra were examined for changes.

Generation of molecular models. The structures of free and chloride complexed $\mathbf{3}$ were created using MM2 force field energy minimization. The energy was reduced to a minimum RMS gradient of 0.100.

The software used was Chem3D Ultra 8.0 supplied by Cambridge Scientific Computing, Inc.

ACKNOWLEDGMENT We thank Enterprise Ireland, grant code SC/2002/161, Science Foundation Ireland for support under the Adaptive Information Cluster award (SFI03/IN3/1361) and the Environmental Protection Agency, Ireland, funding code EPA2004-RS-AIC-M4. We thank Prof. Tony McKervey for his teaching skills and inspiration over the years.

Supporting Information Available: Additional figures (Figures S1-S4). This material is available free of charge via the internet at http://pubs.acs.org.

\section{REFERENCES}

(1) Gutsche, C. D. Calixarenes; The Royal Society of Chemistry: Cambridge, London, 1989.

(2) Gutsche, C. D. Calixarenes Revisited; The Royal Society of Chemistry: Cambridge, London, 1998.

(3) Diamond, D.; Nolan, K. Analytical Chemistry 2001, 73, 22a-29a.

(4) Bohmer, V. Angewandte Chemie-International Edition in English 1995, 34, 713-745.

(5) Mandolini, L.; Ungaro, R.; Editors Calixarenes in Action, 2000.

(6) Diamond, D.; McKervey, M. A. Chemical Society Reviews 1996, 25, 15-24.

(7) Ikeda, A.; Shinkai, S. Chemical Reviews (Washington, D. C.) 1997, 97, 1713-1734.

(8) O' Connor, K. M.; Arrigan, D. W. M.; Svehla, G. Electroanalysis 1995, 7, 205-215.

(9) Arnaud-Neu, F.; Schwing-Weill, M. J. Synthetic Metals 1997, 90, 157-164.

(10) Steed, W. S., Atwood, J. L. Supramolecular Chemistry; Wiley and Sons: Chichester, 2000.

(11) Cadogan, A. M.; Diamond, D.; Smyth, M. R.; Deasy, M.; Mckervey, M. A.; Harris, S. J. Analyst 1989, 114, 1551-1554.

(12) McKittrick, T.; Diamond, D.; Marrs, D. J.; OHagan, P.; McKervey, M. A. Talanta 1996, $43,1145-1148$.

(13) Cadogan, F.; Kane, P.; McKervey, M. A.; Diamond, D. Analytical Chemistry 1999, 71, $5544-5550$.

(14) Bianchi, A., Kristin Bowman, J., Enrique Garcia, E. Supramolecular Chemistry of Anions, 1997.

(15) Beer, P. D.; Gale, P. A. Angewandte Chemie, International Edition 2001, 40, 486-516.

(16) Gale, P. A. Coordination Chemistry Reviews 2000, 199, 181-233.

(17) Gale, P. A. Coordination Chemistry Reviews 2001, 213, 79-128.

(18) Gale, P. A. Coordination Chemistry Reviews 2003, 240, 191-221. 
(19) Hay, B. P.; Firman, T. K.; Moyer, B. A. Journal of the American Chemical Society 2005, 127, 1810-1819.

(20) Bowman-James, K. Accounts of Chemical Research 2005, 38, 671-678.

(21) Sessler, J. L.; Sansom, P. I.; Andrievsky, A.; Kral, V. Supramolecular Chemistry of Anions 1997, 355-419.

(22) Lee, K. H.; Hong, J. I. Tetrahedron Letters 2000, 41, 6083-6087.

(23) Turner, D. R.; Pastor, A.; Alajarin, M.; Steed, J. W. Structure and Bonding (Berlin, Germany) 2004, 108, 97-168.

(24) Lang, K.; Curinova, P.; Dudic, M.; Proskova, P.; Stibor, I.; St'astny, V.; Lhotak, P. Tetrahedron Letters 2005, 46, 4469-4472.

(25) St'astny, V.; Stibor, I.; Petrickova, H.; Sykora, J.; Lhotak, P. Tetrahedron 2005, 61, 99909995.

(26) Nabeshima, T.; Saiki, T.; Iwabuchi, J.; Akine, S. Journal of the American Chemical Society 2005, 127, 5507-5511.

7211.

(27) Stastny, V.; Lhotak, P.; Michlova, V.; Stibor, I.; Sykora, J. Tetrahedron 2002, 58, 7207-

(28) Budka, J.; Lhotak, P.; Michlova, V.; Stibor, I. Tetrahedron Letters 2001, 42, 1583-1586.

(29) Nam, K. C.; Kang, S. O.; Jeong, H. S.; Jeon, S. Tetrahedron Letters 1999, 40, 7343-

7346.

(30) Chrisstoffels, L. A. J.; de Jong, F.; Reinhoudt, D. N.; Sivelli, S.; Gazzola, L.; Casnati, A.; Ungaro, R. Journal of the American Chemical Society 1999, 121, 10142-10151.

(31) Scheerder, J.; vanDuynhoven, J. P. M.; Engbersen, J. F. J.; Reinhoudt, D. N. Angewandte Chemie-International Edition in English 1996, 35, 1090-1093.

(32) Scheerder, J.; Engbersen, J. F. J.; Casnati, A.; Ungaro, R.; Reinhoudt, D. N. Journal of Organic Chemistry 1995, 60, 6448-54.

(33) Scheerder, J.; Fochi, M.; Engbersen, J. F. J.; Reinhoudt, D. N. Journal of Organic Chemistry 1994, 59, 7815-20.

(34) Pelizzi, N.; Casnati, A.; Friggeri, A.; Ungaro, R. Journal of the Chemical Society-Perkin Transactions 2 1998, 1307-1311.

(35) Lee, H. K.; Oh, H.; Nam, K. C.; Jeon, S. Sensors and Actuators B-Chemical 2005, 106, 207-211.

(36) Cho, Y. L.; Rudkevich, D. M.; Shivanyuk, A.; Rissanen, K.; Rebek, J., Jr. Chemistry--A European Journal 2000, 6, 3788-3796.

(37) Mogck, O.; Bohmer, V.; Vogt, W. Tetrahedron 1996, 52, 8489-8496.

(38) Rebek, J., Jr. Chemical Communications (Cambridge) 2000, 637-643.

(39) Zeng, Z.; He, Y.; Meng, L. Huaxue Jinzhan 2005, 17, 254-265.

(40) Wolfbeis, O. S. Journal of Materials Chemistry 2005, 15, 2657-2669.

(41) Wang, Y.; Jin, W. Huaxue Jinzhan 2003, 15, 178-185.

(42) Epstein, J. R.; Walt, D. R. Chemical Society Reviews 2003, 32, 203-214.

(43) Fabbrizzi, L.; Licchelli, M.; Parodi, L.; Poggi, A.; Taglietti, A. Journal of Fluorescence 1998, 8, 263-271.

(44) Bren, V. A. Russian Chemical Reviews 2001, 70, 1017-1036.

(45) Callan, J. F.; de Silva, A. P.; Magri, D. C. Tetrahedron 2005, 61, 8551-8588.

(46) Bell, J. W.; Hext, N. M. Chemical Society Reviews 2004, 33, 589-598.

(47) deSilva, A. P.; Gunaratne, H. Q. N.; Gunnlaugsson, T.; Huxley, A. J. M.; McCoy, C. P.; Rademacher, J. T.; Rice, T. E. Chemical Reviews 1997, 97, 1515-1566.

(48) Sauer, M. Angewandte Chemie, International Edition 2003, 42, 1790-1793.

(49) Cho, E. J.; Moon, J. W.; Ko, S. W.; Lee, J. Y.; Kim, S. K.; Yoon, J.; Nam, K. C. Journal of the American Chemical Society 2003, 125, 12376-12377.

(50) Ren, J.; Wang, Q.; Qu, D.; Zhao, X.; He, T. Chemistry Letters 2004, 33, 974-975.

(51) Xie, H.; Yi, S.; Yang, X.; Wu, S. New Journal of Chemistry 1999, 23, 1105-1110. 
(52) Esteban-Gomez, D.; Fabbrizzi, L.; Licchelli, M.; Sacchi, D. Journal of Materials Chemistry 2005, 15, 2670-2675.

(53) Gunnlaugsson, T.; Ali, H. D. P.; Glynn, M.; Kruger, P. E.; Hussey, G. M.; Pfeffer, F. M.; Santos, C. M. G.; Tierney, J. Journal of Fluorescence 2005, 15, 287-299.

(54) Kim, S. K.; Singh, N. J.; Kim, S. J.; Swamy, K. M. K.; Kim, S. H.; Lee, K.-H.; Kim, K. S.; Yoon, J. Tetrahedron 2005, 61, 4545-4550.

(55) Gunnlaugsson, T.; Davis, A. P.; O'Brien, J. E.; Glynn, M. Organic \& Biomolecular Chemistry 2005, 3, 48-56.

(56) Przygorzewska, J.; Rakoczy, P.; Rokicki, G. Wiadomosci Chemiczne 2003, 57, 43-62.

(57) Forster, T.; Kasper, K. Zeitschrift Fur Elektrochemie 1955, 59, 976-980.

(58) Birks, J. B. Reports on Progress in Physics 1975, 38, 903-74.

(59) Lee, S. H.; Kim, J. Y.; Kim, S. K.; Lee, J. H.; Kim, J. S. Tetrahedron 2004, 60, 5171-

5176.

(60) Jin, T. Chemical Communications 1999, 2491-2492.

(61) Jin, T.; Ichikawa, K.; Koyama, T. Journal of the Chemical Society-Chemical Communications 1992, 499-501.

(62) Kim, J. S.; Shon, O. J.; Rim, J. A.; Kim, S. K.; Yoon, J. Journal of Organic Chemistry 2002, 67, 2348-2351.

(63) Kim, S. K.; Lee, S. H.; Lee, J. Y.; Lee, J. Y.; Bartsch, R. A.; Kim, J. S. Journal of the American Chemical Society 2004, 126, 16499-16506.

(64) Saudan, C.; Ceroni, P.; Vicinelli, V.; Maestri, M.; Balzani, V.; Gorka, M.; Lee, S. K.; van Heyst, J.; Vogtle, F. Dalton Transactions 2004, 1597-1600.

(65) Jin, T.; Monde, K. Chemical Communications 1998, 1357-1358.

(66) Kim, S. K.; Kim, S. H.; Kim, H. J.; Lee, S. H.; Lee, S. W.; Ko, J.; Bartsch, R. A.; Kim, J. S. Inorganic Chemistry 2005, 44, 7866-7875.

(67) Gorbunova, M. G.; Brown, G. M.; Goretzki, G.; Custelcean, R.; Bonnesen, P. V.; Dabestani, R. Abstracts of Papers, 230th ACS National Meeting, Washington, DC, United States, Aug. 28-Sept. 1, 2005 2005, ORGN-014.

(68) Talanova, G. G.; Vedernikova, E. Y.; Staunton, E. A.; Talanov, V. S. Abstracts of Papers, 230th ACS National Meeting, Washington, DC, United States, Aug. 28-Sept. 1, 2005 2005, INOR-110.

(69) Suzuki, Y.; Morozumi, T.; Nakamura, H.; Shimomura, M.; Hayashita, T.; Bartsh, R. A. Journal of Physical Chemistry B 1998, 102, 7910-7917.

(70) Ludwig, R.; Dzung, N. T. K. Sensors 2002, 2, 397-416.

(71) Kim, S. K.; Bok, J. H.; Bartsch, R. A.; Lee, J. Y.; Kim, J. S. Organic Letters 2005, 7, 4839-4842.

(72) Liao, J. H.; Chen, C. T.; Fang, J. M. Organic Letters 2002, 4, 561-564.

(73) Lee, J. Y.; Kim, S. K.; Jung, J. H.; Kim, J. S. Journal of Organic Chemistry 2005, 70, $1463-1466$.

(74) Lee, J. E.; Kim, J. H.; Choi, S. J.; Han, T. H.; Uhm, D. Y.; Kim, S. J. Pflugers ArchivEuropean Journal of Physiology 2002, 444, 619-626.

(75) Sasaki, S.-i.; Citterio, D.; Ozawa, S.; Suzuki, K. Journal of the Chemical Society, Perkin Transactions 2 2001, 2309-2313.

(76) Werner, F.; Schneider, H. J. Helvetica Chimica Acta 2000, 83, 465-478.

(77) Schazmann, B.; McMahon, G.; Nolan, K.; Diamond, D. Supramolecular Chemistry 2005, 17, 393-399.

(78) Winnik, F. M. Chemical Reviews 1993, 93, 587-614.

(79) Yang, J. S.; Lin, C. S.; Hwang, C. Y. Organic Letters 2001, 3, 889-892.

Vol. 4.

(80) Lakowicz, J. R. Topics in Fluorescence Spectroscopy; Plenum Press: New York, 1994;

(81) Wolfbeis, O. S. Analytical Chemistry 2000, 72, 81r-89r. 
(82) Wolfbeis, O. S. Analytical Chemistry 2002, 74, 2663-2677.

(83) Wolfbeis, O. S. Analytical Chemistry 2004, 76, 3269-3283.

(84) Dasgupta, P. K.; Eom, I.-Y.; Morris, K. J.; Li, J. Analytica Chimica Acta 2003, 500, 337-

364.

(85) Emsley, J. Nature's Building Blocks; Oxford University Press: Oxford, 2003.

(86) Duxbury, A. C.; Duxbury, A. B. An introduction to the world's oceans; fifth ed.; WCB Publishers: London, 1997.

(87) Gutsche, C. D.; Levine, J. A. Journal of the American Chemical Society 1982, 104, 26522653.

(88) Gutsche, C. D.; Levine, J. A.; Sujeeth, P. K. Journal of Organic Chemistry 1985, 50, 5802-5806.

(89) Kammerer, H.; Happel, G.; Bohmer, V.; Rathay, D. Monatshefte Fur Chemie 1978, 109, 767-773.

(Footnotes at end of document)

\section{SYNOPSIS TOC}

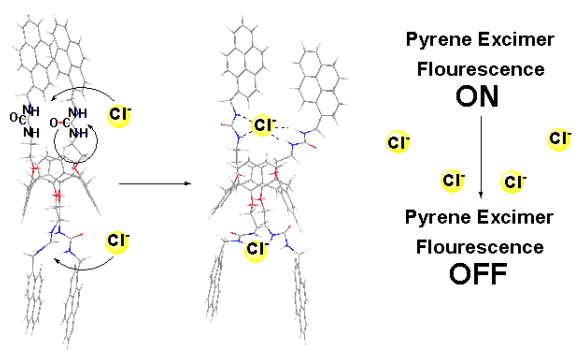


i The structures of free and chloride complexed 3 were created using MM2 force field energy minimization. The energy was reduced to a minimum RMS gradient of 0.100 . The software used was Chem 3D Ultra 8.0 supplied by Cambridge Scientific Computing, Inc.

ii The association constant was calculated by non-linear regression analysis and the fitting of experimental data with a standard fluorescence equation by minimizing the sum of square residuals. The standard Microsoft Excel add-in SOLVER was used.

${ }^{i i i}$ Roithner Laser Technik, Vienne, Austria, www.roithner-laser.com 